\title{
The Effect of Cilia and the Mucociliary Clearance on Successful Drug Delivery
}

\author{
Sveinbjörn Gizurarson
}

Faculty of Pharmaceutical Sciences, University of Iceland; Hofsvallagata 53, 107 Reykjavik, Iceland. Received May 28, 2014; accepted January 26, 2015; advance publication released online February 7, 2015

\begin{abstract}
Nasal mucociliary clearance is one of the most important factors affecting nasal delivery of drugs and vaccines. This is also the most important physiological defense mechanism inside the nasal cavity. It removes inhaled (and delivered) particles, microbes and substances trapped in the mucus. Almost all inhaled particles are trapped in the mucus carpet and transported with a rate of $8-10 \mathrm{~mm} / \mathrm{h}$ toward the pharynx. This transport is conducted by the ciliated cells, which contain about 100-250 motile cellular appendages called cilia, $0.3 \mu \mathrm{m}$ wide and $5 \mu \mathrm{m}$ in length that beat about 1000 times every minute or $12-15 \mathrm{~Hz}$. For efficient mucociliary clearance, the interaction between the cilia and the nasal mucus needs to be well structured, where the mucus layer is a tri-layer: an upper gel layer that floats on the lower, more aqueous solution, called the periciliary liquid layer and a third layer of surfactants between these two main layers. Pharmacokinetic calculations of the mucociliary clearance show that this mechanism may account for a substantial difference in bioavailability following nasal delivery. If the formulation irritates the nasal mucosa, this mechanism will cause the irritant to be rapidly diluted, followed by increased clearance, and swallowed. The result is a much shorter duration inside the nasal cavity and therefore less nasal bioavailability.
\end{abstract}

Key words cilia; mucine; mucociliary clearance; mucus; pharmacokinetics

\section{INTRODUCTION}

The development of intranasal drugs and vaccines should be carried out in such a way that it does not affect normal functions of the nose. Everything we insert into the nose may affect normal nasal function, although the nose is well equipped in dealing with these issues. This review will focus on one of these defense mechanisms, the cilia and the mucociliary clearance and how drug and vaccine delivery may be affected by this mechanism.

Nasal mucociliary clearance is one of the most important factors affecting nasal delivery of drugs and vaccines. The anatomy of the nasal cavity supports this clearance by providing a slope downwards towards the pharynx. The mucociliary clearance is also the most important physiological defense mechanism inside the nasal cavity. It removes inhaled (and delivered) particles, microbes and substances trapped in the mucus. It is estimated that the airway mucus trap up to 25 million particles an hour. ${ }^{1)}$ The ciliated cells are the most frequent cell type in the nasal cavity. ${ }^{2-4)}$ Their function is to provide a coordinated sweeping motion of the mucus coat to the throat, called ciliary escalator, ciliary clearance or mucociliary clearance. This system transports the mucus to the nasopharynx, where after it is swallowed.

One of the first description of the cilia are from $1835^{5}$ and when electron microscopy became available, the anatomy of their inner structure became visible and was characterized. ${ }^{6}$ Each cell contain about 100-250 motile cellular appendage called cilia, $0.3 \mu \mathrm{m}$ wide and $5 \mu \mathrm{m}$ in length that beat about 1000 times every minute or $12-15 \mathrm{~Hz}^{7-9)}$ This nanomachine is composed of over 600 proteins in addition to various enzymes and other molecular complexes involved in their motility ${ }^{10}$ and numerous mitochondria are found in the cytoplasm in the apical part, assigns of an active metabolism in that region of the cell. This function together with a great number of submucosal glands and goblet cells providing the surface fluids, con- struct the mucociliary system. While early studies of mammalian cilia focused on their strokes, biochemical mechanism and their mucociliary function, recent research have showed that they also function as sensory cellular antennae, coordinating a plethora of cellular signaling pathways ${ }^{11,12}$ and have been linked with diseases such as polycystic kidney disease. ${ }^{12)}$

As previously mentioned, the mucociliary clearance is one of the fundamental functions required to maintain the health and defense of the nose. Based on a surface area of about $160 \mathrm{~cm}^{2}$ in a normal human nose, there is about $20-40 \mathrm{~mL}$ of mucus secreted and transported daily to the pharynx although some articles claim that $1-2 \mathrm{~L}$ of mucus are produced per day. ${ }^{13)}$ The efficacy of this defense function is such that about $80-100 \%$ of particles larger than $4-12.5 \mu \mathrm{m}$ is trapped in this mucus carpet and removed. ${ }^{14,15)}$

Several studies have been carried out on the mucociliary transport in humans, ${ }^{16-20)}$ where particles are placed on selected sites inside the nasal cavity and followed. Using radioactive particles, their transport may be observed using a $\gamma$-camera. Figure 1 show the direction of mucus transport inside the nose. Particles placed on the septum travel posteriorly and downwards to the soft palate and to the inferior edge of the septum. Particles placed on the nasal floor travel posteriorly and deviate either laterally to the inferior meatus or medially towards the inferior edge of the nasal septum on their way to the nasopharynx. Particles placed on the surface of the inferior conchae pass laterally to the inferior meatus and then posteriorly towards nasopharynx.

There mucociliary transport rate differ between regions in the nasal cavity and depends on the density of the ciliated cells, the length of the cilia and the mucus quality. ${ }^{19)}$ The mucociliary transport rate is $1-2 \mathrm{~mm} / \mathrm{h}$ just behind the anterior site of the inferior conchae and gradually increases to a speed from $8-10 \mathrm{~mm} / \mathrm{h}^{14)}$ up to $10 \mathrm{~mm} / \mathrm{min}$ in the posterior part ${ }^{20)}$ of the nasal cavity such as the inferior conchae. The individual variation may, however, be high. ${ }^{15,16,20)}$ The average clearance 

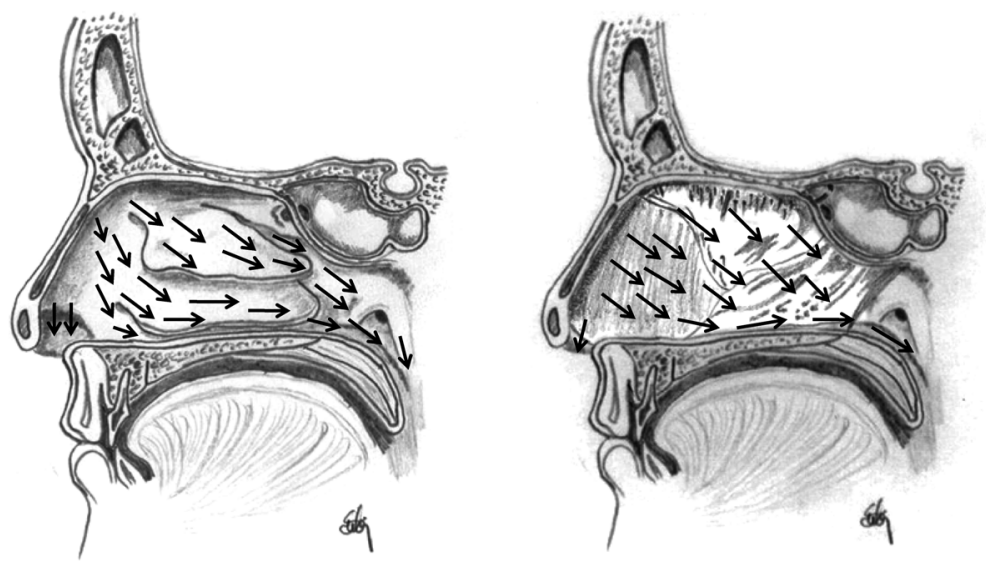

Fig. 1. Sagittal Section Showing the Mucociliary Clearance Pathways on the Lateral (Left) and Nasal Septum (Right)

Table 1. The Functions of Mucus (Adapted from Ref. 1)

- Physical barrier to inhaled airborne particles, irritants, microbes and to administered drugs, vaccines and formulations

- Entrapment of organisms, particles, irritants and other compounds

- Formation of vehicle on which irritants, drugs or vaccines are transported/cleared by the mucociliary system to the pharynx and swallowed.

- Provide a waterproof layer over the epithelium to limit dehydration.

- Humidification of inspired air

- Insulation

- $\mathrm{pH}$ buffering capacity

- Lubrication

- Neutralization of toxic substances (drugs, vaccines, excipients, gases)

- Selective macromolecular sieve

- Source of antibacterial and other protective enzymes, and provision of extracellular surface for their activity

- Source of immunoglobulins and provision of extracellular surface for their activity

time for an adult, free from nasal disease, is about $7-15 \mathrm{~min}$ based on a saccharin test. ${ }^{21-24)}$ If the subjects were fasting (e.g. waiting to go to a nasal procedure) the average clearance was measured to be $13.3 \mathrm{~min}(5.3-32.5 \mathrm{~min})$. Patients having allergy or rhinitis are likely to have accelerated mucociliary transport, which is mainly due to changes in the rheological properties of the mucus in addition to an increased ciliary beat frequency. But some data actually show the opposite. ${ }^{24-27)}$

\section{MUCUS}

The mucus is a viscoelastic gel that forms a $10-15 \mu \mathrm{m}$ thin protective film on the surface of the nasal mucosa. It is a complex aqueous solution of lipids, glycoconjugates and proteins. Its composition and structure makes it an important defense mechanism that has the capability to protect the underlying cells from epithelial damage caused by drugs, vaccines, excipients, nasal formulations or inhaled irritants. The nasal mucus effectively filters and removes nearly $100 \%$ of particles greater than $4 \mu \mathrm{m}$ in diameter ${ }^{15)}$ in addition to other functions as listed in Table 1. Under normal circumstances the mucus has the capability to entrap bacteria, viruses and even compounds such as drugs, peptides and proteins and clear them down to the nasopharynx, then otopharynx and hypopharynx from where the secretions are swallowed. ${ }^{28)}$ When swallowed it enters the gastrointestinal tract for degradation. It has a protective role in viral infections such as human immunodeficiency virus (HIV), where it prevent the transmission of pathogens by inhibiting viral replication, immobilize them into the mucusviral complex and kill them. ${ }^{29,30)}$ Mucins have been shown to have associations with various cellular pathways, affecting cell growth, cell-cell interactions and cellular response to immunity. ${ }^{31)}$ This has resulted in various diagnostic assays for different diseases such as adenocarcinoma, where epitopes found on mucins are recognized.

The mucus has a remarkable ability to humidify inspired air. When cold dry air is inhaled through the nose, the nasal mucosa is able to humidify it to $98 \%$ and warm it to $30^{\circ} \mathrm{C} .{ }^{32}$ The tip of the beating cilia contain fine hair or fingers that ensure the flow of the mucus carpet each time they perform an effective stroke as shown in Fig. 2. The mucus is slightly acidic, with $\mathrm{pH}$ between 5.5 and $6.5{ }^{13}$ ) Several drugs such as expectorants, compounds that irritate the mucosa or causes hypersecretion of mucus, affect the viscosity and the composition of the mucus.

For efficient mucociliary clearance, there need to be a well structured interaction between the cilia and the nasal mucus. The mucus layer must be a liquid bi-layer (or a tri-layer); an upper gel layer that floats on the lower, more aqueous solution, called periciliary liquid layer. Some research groups do also describe the third layer of surfactants, between these two main layers. ${ }^{33,34)}$ The periciliary layer is an aqueous solution, containing various electrolytes such as sodium $\left(\mathrm{Na}^{+}\right)$and chlorine $\left(\mathrm{Cl}^{-}\right)$that allows the cilia to move freely between each effective stroke as shown in Fig. 2. The composition of the mucus is shown in Table 2. The function of the mucus is also lubrication to the beating cilia, where it contains various electrolytes necessary for the epithelial membrane. The chlorine pump located on the cellular surface pump fluid to the mucosal secretion. ${ }^{35)}$

The depth or thickness of the periciliary fluid is the key factor in mucociliary clearance. If excessive, the ciliary fingers will fail to grab or contact the gel-layer. ${ }^{36)}$ The thickness of the layer varies between cell types and is about $7 \mu \mathrm{m}$ over ciliated cells and $3 \mu \mathrm{m}$ over goblet and non-ciliated columnar cells. ${ }^{37)}$ The periciliary layer also acts as a reservoir that accepts and donates liquid to maintain optimal conditions for the tips of the cilia to move the mucin containing layer.

The surfactant layer facilitates the spreading of mucus over 


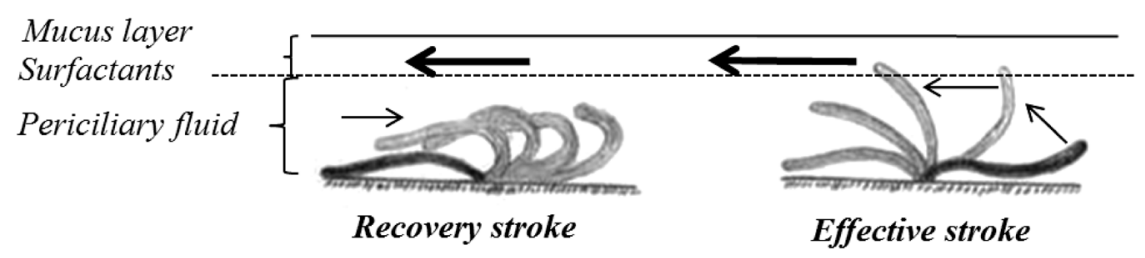

Fig. 2. Airway Mucus Secretion

In healthy airways, mucus forms a bi-layer above the epithelium, with surfactant (dotted line) separating the gel and sol layers. Modified picture from Song $e t$ al. ${ }^{65)} \mathrm{Mu}$ cins secreted by goblet cells and submucosal glands confer viscoelasticity on the mucus, which facilitates mucociliary clearance of inhaled particles and irritants. Mucus hydration is regulated by salt (and water) flux across the epithelium. The glands also secrete water. Plasma proteins exuded from the tracheobronchial microvasculature bath the submucosa and contribute to the formation of mucus. The above processes are under the control of nerves and regulatory mediators. The cilia can only transport mucus if it has appropriate viscoelasticity. The periciliary layer, has lower viscosity allowing the cilia to move freely below the viscous mucus blanket, then reaching into the blanket and transport it towards the nasopharynx.

Table 2. The Composition of Mucus

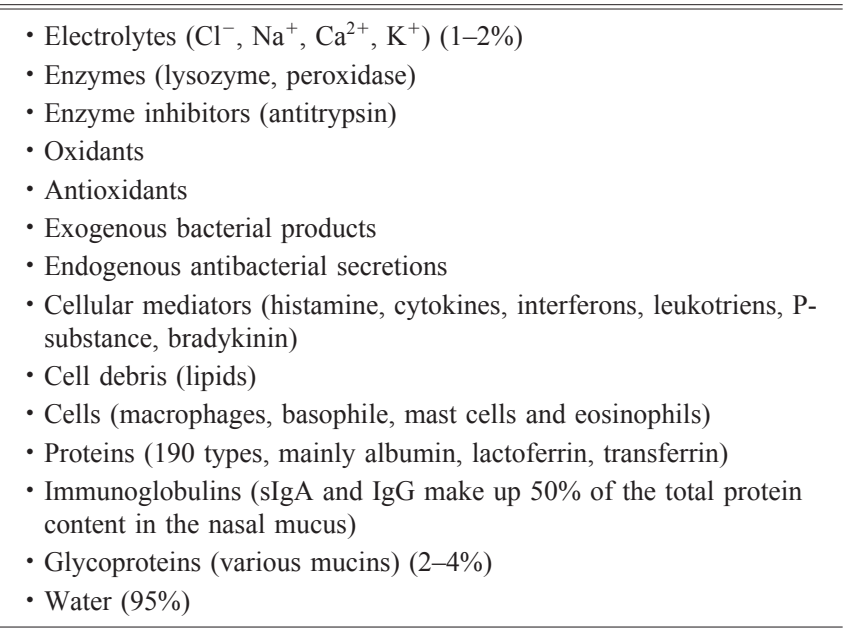

In case there are pathogenic conditions, there is an intense change in the mucus composition.

the epithelial surface and allows the upper, gel layer to flow freely towards the pharynx, although the periciliary fluid flows back and forth, due to each ciliary stroke. The upper gel layer has the optimal viscosity, elasticity (viscoelasticity) and flow resistance to establish a sticky layer that traps particles. ${ }^{38)}$ The high molecular-weight mucous glycoproteins, mucins, are responsible for the viscoelastic characteristics of the upper mucus layer. The viscoelastic property of the mucus has the major influence on the mucociliary transport. ${ }^{39)}$ In addition to its viscoelastic properties it shows a thixotrophic characteristics (shear-thinning), cohesive- and adhesiveness.

Formulations administered to nasal mucosa, enters the mucus layer, causing it to swell and may affect the interaction between cilia and mucus. It is common that mucus transport rates actually increase following drug delivery. ${ }^{40)}$ The mucus carpet renews itself every $20-30 \mathrm{~min}$, although these values vary much, even among normal individuals. ${ }^{28)}$

\section{MUCIN}

The mucins are produced by the goblet cells, anterior nasal glands, epithelial secretory cells and the seromucous glands in the submucosal and comprise up to $2 \%$ by weight of the airway mucus. ${ }^{41-43)}$ In addition, tears and transudation from blood vessels add fluid to the nasal secretions. They are a long, thread-like, complex glycoconjugates consisting of a linear peptide backbone (apomucin), which is encoded by spe-
Table 3. Membrane-Associated Mucins and Gel-Forming Mucins Found in the Nasal Mucosa

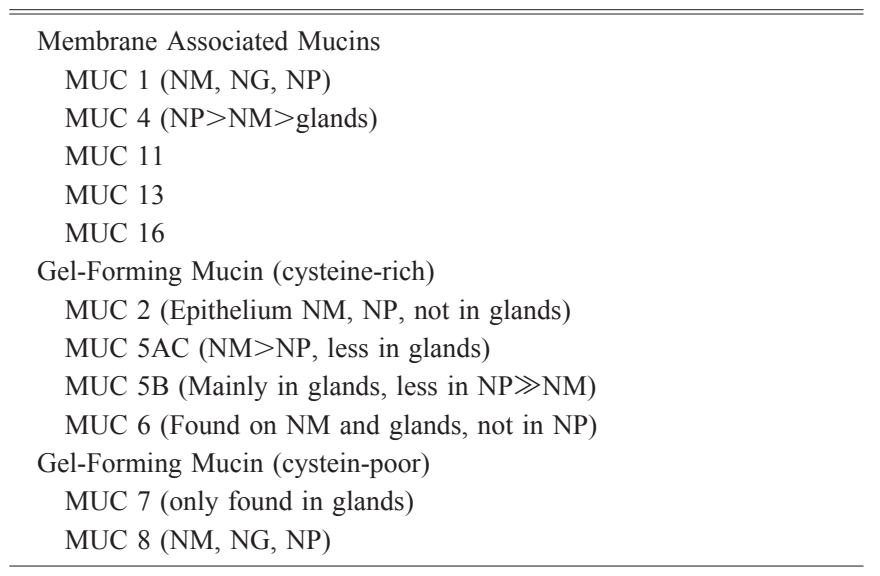

$\mathrm{NM}=$ nasal mucosa, $\mathrm{NG}=$ nasal glands, $\mathrm{NP}=$ nasal polyps.

Table 4. The Effect of Drugs and Excipients on the Mucus (Adapted from Ref. 2)

\begin{tabular}{|c|c|}
\hline Formulations/Excipients & Effect \\
\hline Hypertonic (saline) & Increase secretion \\
\hline Mannitol & Increase secretion \\
\hline Drugs & Effect \\
\hline$N$-Acetylcysteine & Severs disulfide bonds \\
\hline Dornase alfa & Mucolytics \\
\hline Guaifenesin & No effect \\
\hline Heparin & Mucolytics \\
\hline Nacystelyn & Increase $\mathrm{Cl}$ secretion \\
\hline Thymosin $\beta 4$ & Mucolytics \\
\hline
\end{tabular}

cific mucin (MUC) genes. These are hundreds of carbohydrate O-linked side-chains and N-linked glycans linked together. The glycosylation pattern is complex, polydispersed and extremely diverse and is associated with complementary motifs on bacterial cell walls, which facilitates broad-spectrum bacterial attachment and subsequent clearance. ${ }^{44)}$ These complex glycoproteins form disulfide-linked oligomers or multimers with molecular weights in the millions, but may also be fragmented, by reduction, to create monomers. ${ }^{45)}$

There are at least 2 structurally and functionally distinct classes of mucin, the membrane-associated mucins and the secreted mucins, which are either gel-forming or nongelforming mucins ${ }^{2)}$ as shown in Table 3 . The membrane associated mucins contribute to the formation of the epithelial 


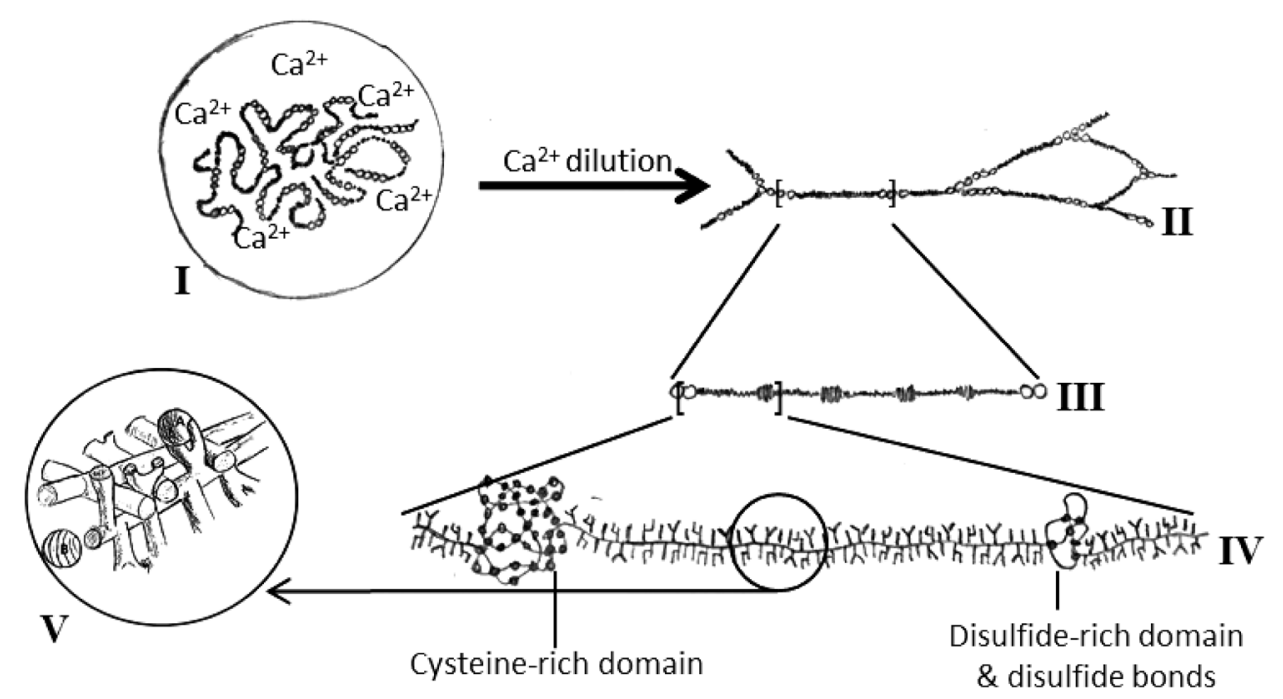

Fig. 3. Nasal Gel-Forming Mucin

Picture modified from Lai et al. ${ }^{89)}$ (I) The mucin is well packed and stored in a granule e.g. by the mean of Ca ions; (II) Upon release the mucin unfolds and expands; (III) Each mucin monomer is approximately $500 \mathrm{~nm}$ in length and comprises of amino acid backbone with highly glycosylated (linear) domains and folded regions. These monomers are cross-linked via disulphide bonds; (IV) Individual structural arrangement mucin glycoprotein showing different domains; (V) Structure of two mucin glycoproteins zipped together. Multiple zipped glycoproteins will build up the final mucus carpet or mucus-gel covering the surface of the nasal epithelium.

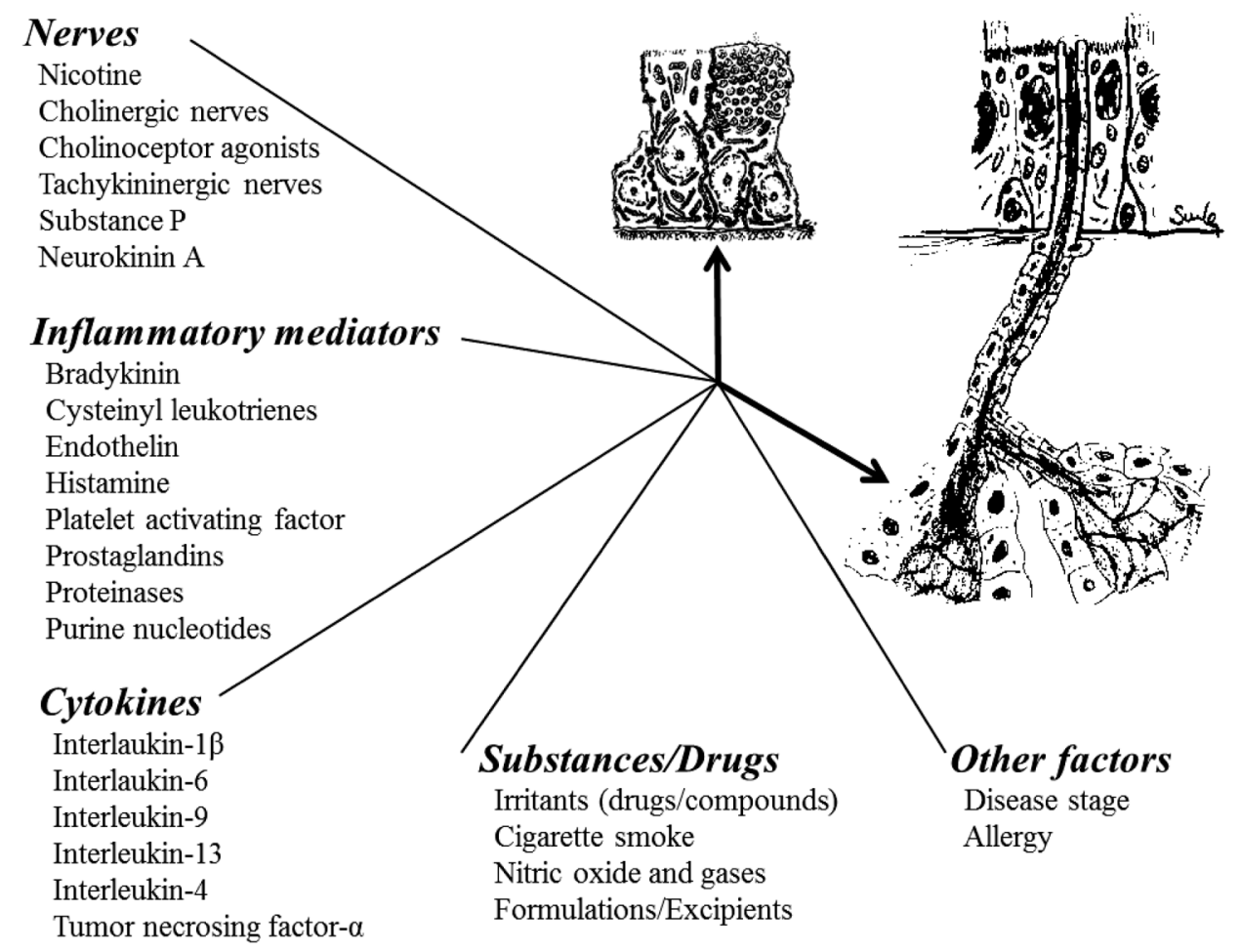

Fig. 4. The Secretion of Mucin and Mucus Is Controlled by Several Factors from Different Sources

The figure shows some of the factors affecting the secretion to the nasal mucosa.

surface where the secretory mucins are stored in intracellular secretory granules. They are released to the apical surface of the cell in response to a stimulus. The MUC5AC is different from the others since it is not polymorphic and its production is restricted to goblet cells. MUC5AC together with MUC5B are the major contributors to the rheological properties and the structure of the mucus. ${ }^{46-48)}$ MUC2, however, is found concurrent irritation of the nasal mucosa. ${ }^{2,49)}$ The composition of normal mucus is altered depending on the relative contribution to the secretions of these different cellular sources and the disease stage of the subject. ${ }^{49,50)}$

Each MUC has its own characteristics, function and ability. It is a single polypeptide chain of 357 amino acids. ${ }^{51)}$ The MUC7 peptide for example has a sequence of five distinct domains: (a) a histatin-like N-terminal, having a leucine-zipper segment, (b) a moderately glycosylated domain, (c) six heavily glycosylated tandem repeats each consisting of 23 amino acids, (d) another heavily glycosylated MUC1- and MUC2-like domain, and (e) a C-terminal leucine-zipper segment.

Inside the goblet cells and other mucin producing cells, the 
Table 5. Formulation Factors Affecting Mucociliary Clearance

\begin{tabular}{lcc}
\hline \hline Factor & Effect & References \\
\hline Bioadhesion & Inhibit & \\
Concurrent air flow & Inhibit/stimulate & \\
Dryness & Inhibit & $53)$ \\
Hypertonic $(>1.5 \% \mathrm{NaCl})$ & Stop & $8,54)$ \\
Hypotonic $(<0.45 \% \mathrm{NaCl})$ & Inhibit & $8,54)$ \\
Microspheres & Inhibit & $55)$ \\
pH $(>11)$ & Inhibit & $54)$ \\
pH $(<6)$ & Inhibit & $54)$ \\
Temperature $>40^{\circ} \mathrm{C}$ & Inhibit & \\
Temperature $<30^{\circ} \mathrm{C}$ & Inhibit & \\
Viscosity (increased) & Inhibit & \\
\hline
\end{tabular}

Table 6. Drugs That Affect Mucociliary Clearance

\begin{tabular}{|c|c|c|}
\hline Drugs/Compounds & Effect & References \\
\hline Acetylcholine* & Stimulate & 56) \\
\hline Adrenocorticotropic hormone* & Stimulate & 57) \\
\hline Aminophylline & Stimulate & 58) \\
\hline Antazoline & Inhibit & 59) \\
\hline Antihistamine & Inhibit & 60) \\
\hline Atropine & Slight inhibition & 58) \\
\hline Bacitracin & Inhibit & 36) \\
\hline Bethanecol & Stimulate & 61) \\
\hline Bromhexidine & Stimulate & 58) \\
\hline Caffeine & Stimulate & \\
\hline Calcitonin & No effect & 62) \\
\hline Cigarette smoke & Stop/incoordinate & 63) \\
\hline Clenbuterol & No effect & 58) \\
\hline Cocaine & Paralize & 64) \\
\hline Ephedrine & Stimulate & 65) \\
\hline Epinephrine & Stimulate & 66) \\
\hline Fluticasone propionate & No effect & 67) \\
\hline Guaiphenesin & No effect & 58) \\
\hline Hyoscine & Inhibit & 58) \\
\hline Insulin & No effect & $68,69)$ \\
\hline Ipratropium & No effect & 58) \\
\hline Lidocaine & No effect & 70) \\
\hline Menthol & Inhibit & 71) \\
\hline Methyl xanthines & Stimulate & 58) \\
\hline 3-Methoxyquercetin & Inhibit & 72) \\
\hline Morphine & Inhibit & \\
\hline Neomycin sulphate & No effect & 61) \\
\hline Oxymetazoline* & Inhibit & 73) \\
\hline Pilocarpine nitrate & Stimulate & 61) \\
\hline Pontocaine & Stop & 70) \\
\hline Prednisolone & Slight stimulation & 57) \\
\hline Propranolol & Inhibit & 74) \\
\hline$S$-Carboxymethylcystein & No effect & 58) \\
\hline Serotonin & Stimulate & 66) \\
\hline Sodium 2-mercapto-ethan & Stimulate & 58) \\
\hline Terbutaline & No effect & 58) \\
\hline Tripelennamine & Inhibit & 61) \\
\hline Tubocurarine* & No effect/inhibit & 56) \\
\hline Xylometazoline & Inhibit & $59,75)$ \\
\hline
\end{tabular}

* Concentration dependent.
Table 7. Excipients That Affect Mucociliary Clearance

\begin{tabular}{|c|c|c|}
\hline Excipients & Effect & References \\
\hline Actinonin & Stimulate & 76) \\
\hline Ammonium glycyrrhizinate & Inhibit & 62) \\
\hline Aprotinin & Inhibit & 68) \\
\hline Bacitracin & No effect & 76) \\
\hline Benzalconium chloride* & Inhibit (stop) $)^{* *}$ & $62,67,77)$ \\
\hline Bestatin & Stimulate & 76) \\
\hline Cadmium salts & Inhibit & 78) \\
\hline Calcium & Stimulate & 66) \\
\hline Chitosan & No effect & $79,80)$ \\
\hline Chlorbutol & Inhibit & $81,82)$ \\
\hline Chlorhexidine & Slight inhibition & 77) \\
\hline Chlorocresol & Stop & $77,82)$ \\
\hline Dimethylamine & Inhibit & 78) \\
\hline Dimethyl- $\beta$-cyclodextrin & Slight inhibition & 53) \\
\hline $\operatorname{DMSO}(\leq 15 \%)$ & Stimulate & 76) \\
\hline EDTA & Inhibit & 77,82) \\
\hline Hydroxypropyl- $\beta$-cyclodextrin & No effect & 72) \\
\hline L- $\alpha$-Lysophosphatidylcholine & Stop & 69) \\
\hline Methyl-p-hydroxybenzoate & Inhibit & 77) \\
\hline Phenylmercuric borate & Inhibit & $77,82)$ \\
\hline Phenylmercuric nitrate & Inhibit & 77) \\
\hline $\begin{array}{l}\text { L- } \alpha \text {-Phosphatidylcholine, } \\
\text { didecanoate }\end{array}$ & Slight inhibition & 69) \\
\hline Polyoxyethylene-9-lauryl ether & Stop & 69) \\
\hline Potassium & Stimulate & 66) \\
\hline Propyl-p-hydroxybenzoate & Inhibit & 77) \\
\hline Puromycin & No effect & 76) \\
\hline $\begin{array}{l}\text { Quaternary ammonium com- } \\
\text { pounds }\end{array}$ & Inhibit & 60) \\
\hline Ringer solution & No effect & 62) \\
\hline Saline & Slight inhibition & 77) \\
\hline Sodium cholate & Inhibit/stop & 68) \\
\hline Sodium deoxycholate & Stop & 69) \\
\hline Sodium glycocholate & No effect & 69) \\
\hline Sodium taurodihydrofusidate* & Inhibit/stop & 69) \\
\hline Thiomersal & No effect/inhibit & $76,77,82)$ \\
\hline Tween 20 & Inhibition & \\
\hline Tween 80 & Inhibition & 72) \\
\hline
\end{tabular}

* Concentration dependent. **In vivo studies did not have ciliostatic effects.

granules, which contain mucins, are present in the cytoplasm. They are first synthesized on the rough endoplasmic reticulum, then oligomerized and sent to the Golgi for glycosylation followed by subsequent packaging and budding into mature mucin granules. Hereafter they are stored in the cytoplasm, in preparation for release. The glycoproteins are formed by end-to-end associations, linked by disulphide bonds as shown in Fig. 3, making them very large macromolecules. Other intermolecular bonds are also important and contribute to the creation of the viscoelastic structure of the mucus. These are bonds such as ionic bonds, hydrogen bonds and the van der Waal's forces. ${ }^{9)}$

The main control of nasal secretion is autonomic and parasympathetic stimulation, mainly the cholinergic nerves, mediated by acetylcholine. Figure 4 and Table 4 show various components and mediators affecting the stimulation or inhibition of nasal mucus secretion. Upon either an extracellular stimuli or an unregulated secretion, the exocytosis of mucin occur, involving the movement of the mucin granule 
to the apical surface of the goblet cell. At the surface of the mucosa different components are mixed together and become mucus. This movement is dependent upon many factors. Upon release, the unfolding of the mucin is extremely rapid, taking only tens of milliseconds, to expand many hundred-fold. ${ }^{52)}$ This rapid expansion occurs because the polyanionic mucin is highly condensed inside the granules, packed with $\mathrm{Ca}^{2+}$. Upon exocytosis the $\mathrm{Ca}^{2+}$ is rapidly diluted, allowing electrostatic expulsion to occur with water uptake, resulting in many hundred-fold expansion of size.

\section{DRUGS AND FORMULATIONS}

The coordination of the ciliary beats are stimulated and controlled by biochemical signaling. Different factors may affect their function and coordination, such as pharmacological, mechanical (e.g. viscosity of a formulation), physical (e.g. temperature, humidity and air flow), microbacterial, chemical factors (e.g. bioadhesion) and disease stage of the nose. All these factors are important and need to be evaluated since they may speed up, halter or even block the clearance if they do not damage the cilia.

Pharmacological and chemical factors may be divided into substances that affect the structure and mobility of the cilia or substances that affect the biochemistry running the nanomachinery of the cilia. In the latter group calcium binding compounds may be found such as ethylenediaminetetraacetic acid (EDTA) or compounds that interfere with the arachidonic acid metabolism, guanylate cyclase, protein kinase or intracellular ATP. These substances including phosphorylation, cytoplasmic calcium, production of prostaglandins, nitric oxide and cGMP play an important role in ciliary beating. ${ }^{83-85)}$ Concurrent use of drugs such as non-steroidal anti-inflammatory drug (NSAID) drugs may have some effect on the mucociliary clearance through their inhibiting effect on the enzyme cyclooxygenase that regulates the arachidonic acid metabolism. Table 5 list up a formulation factors that affect the ciliary function, Table 6 a number of drugs and Table 7 a number of excipients.

As previously mentioned, the function of the mucus carpet is to protect the cilia from surrounding factors such as temperature etc., but the cilia operate optimally at temperature around $35-40^{\circ} \mathrm{C}$. Outside this range, the natural beat frequency drops. ${ }^{86)}$ Similarly, the cilia are sensitive to dryness. All ciliated cells are covered with about 300 microvilli, a fingerlike cytoplasmic expansion on the surface of the cells. These microvilli prevent the surface of the ciliated cells from drying by retaining essential moisture for ciliary function. These microvilli are uniformly distributed over the entire apical surface. ${ }^{4)}$ Due to that, the surface is increased significantly, providing increased opportunity for absorption.

\section{PHARMACOKINETICS AND MUCOCILIARY CLEARANCE}

Because the rapid clearance of the mucus carpet towards the throat, inhaled drugs and vaccines have a very short window to be absorbed, before they are cleared to the throat and swallowed. Assuming the mucociliary transport rate follows first-order kinetics, having a half-life about $20 \mathrm{~min},{ }^{54,55,87,88)}$ the clearance down to the pharynx $[P]$ or nasopharynx may be

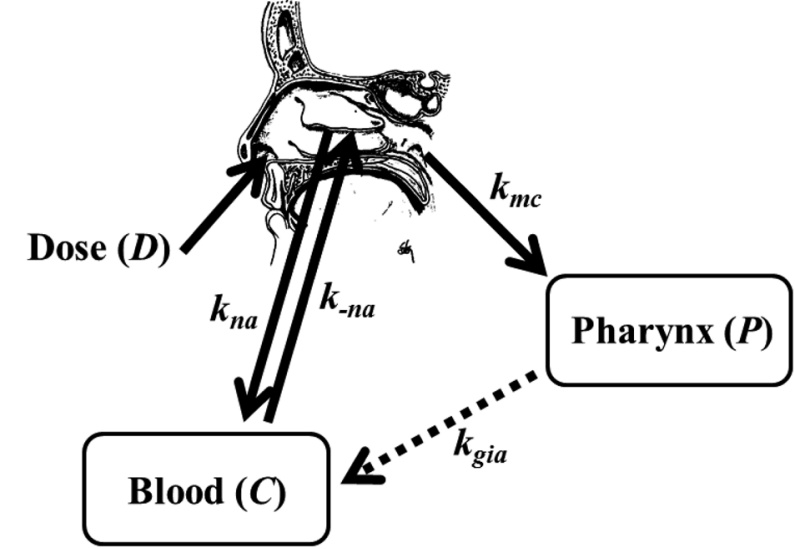

Fig. 5. Graphical Expression of the Fate of Drug Administered into the Nasal Cavity

The mucociliary clearance removes the drug to the pharynx. Some of the drug may be absorbed into the blood circulation. $k_{\mathrm{na}}, k_{-\mathrm{na}}, k_{\mathrm{mc}}$ and $k_{\mathrm{gia}}$ are the nasal absorption, reverse blood to nose transport, mucociliary clearance rate and gastrointestinal absorption rate, respectively.

demonstrated as shown in Fig. 5 where $D$ is the dose, administered into the nasal cavity. The disappearance of the drug from the nasal cavity due to the mucociliary clearance may be expressed as:

$$
\frac{\partial D}{\partial t}=-k_{\mathrm{mc}}[D]
$$

where $\partial D$ is the time dependent change of dose inside the nasal cavity and where the transport rate from nose to pharynx is expressed as $k_{\mathrm{mc}}$. Integrating this equation gives:

$$
[D]_{t}=[D]_{0} e^{-k_{\mathrm{mc}} t}
$$

The mucociliary clearance may be expressed graphically as shown in Fig. 6, where the half-life is $20 \mathrm{~min}$. The figure also show how the clearance pattern will change if the mucociliary clearance rate is haltered e.g. with a formulation having mucoadhesive properties

Injectable vaccines, especially adsorbed vaccines, may stay for weeks or even months at the site of injection, until removed by the immune system. When these gigantic molecules are administered into the nasal cavity, this short half-life may cause them to be eliminated before they are recognized or get transported through the mucus and into the lymphatics.

Supposing that the rate of absorption is faster than the mucociliary clearance, we may calculate the rate of change of the concentration of drug $C$ according to the equation here above. This absorption, from nose-to-blood, may be expressed as follows:

$$
[C]_{t}=\frac{[D]}{V_{\mathrm{d}}} \frac{k_{\mathrm{na}}}{\left(k_{\mathrm{na}}+k_{\mathrm{mc}}\right)}\left(1-e^{-\left(k_{\mathrm{na}}+k_{\mathrm{mc}}\right) t}\right)
$$

where $[C]$ is the concentration in the blood, $V_{\mathrm{d}}$ is the volume of distribution and the absorption rate is expressed as $k_{\mathrm{na}}$. Since the transport from the blood to the nasal cavity is almost zero, $k_{-n a}$ may be eliminated. Figure 7 show a simulation based on values following intranasal administration of zolmitriptan nasal spray. The rate of absorption is around $0.186 \mathrm{ng} /$ $\mathrm{mL} / \mathrm{min}$, giving a serum concentration of around $2.79 \mathrm{ng} / \mathrm{mL}$ after $15 \mathrm{~min}$, when $5 \mathrm{mg}$ is administered intranasally. 


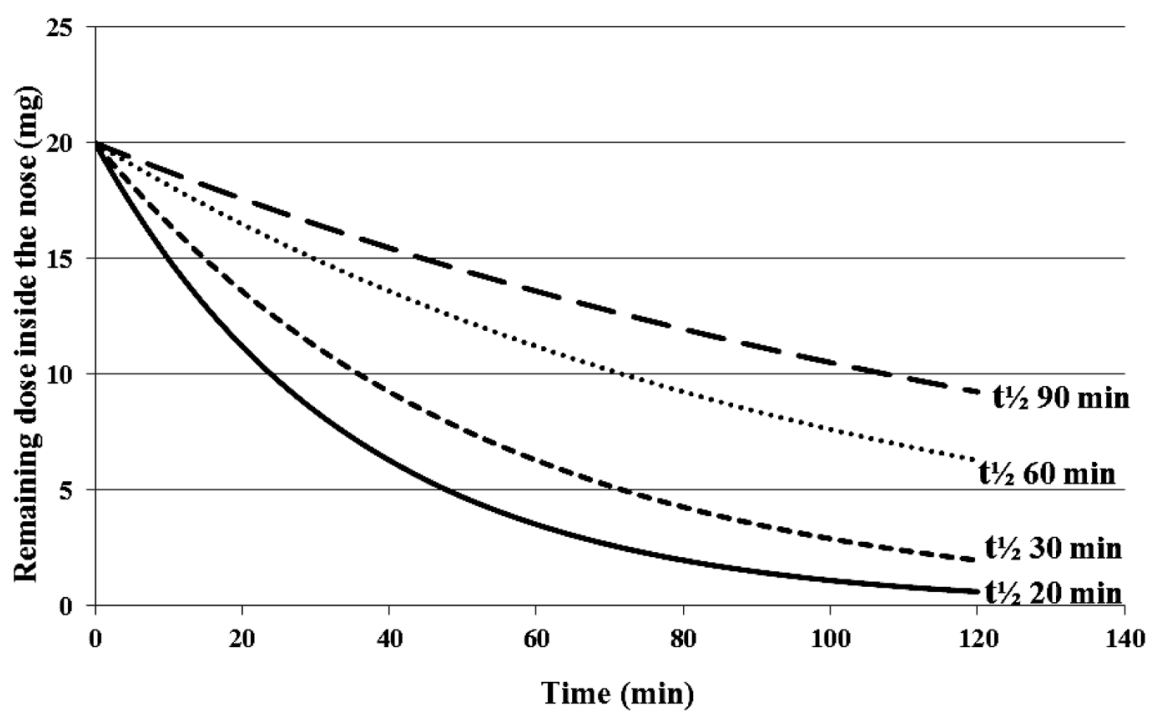

Fig. 6. A Compound Administered into the Nasal Cavity (Suggested Dose: $20 \mathrm{mg}$ ) Will Be Removed Down to the Pharynx and Swallowed According to the Solid Line

The figure also show how the drug may be retained inside the nasal cavity if the clearance is haltered (dotted lines).

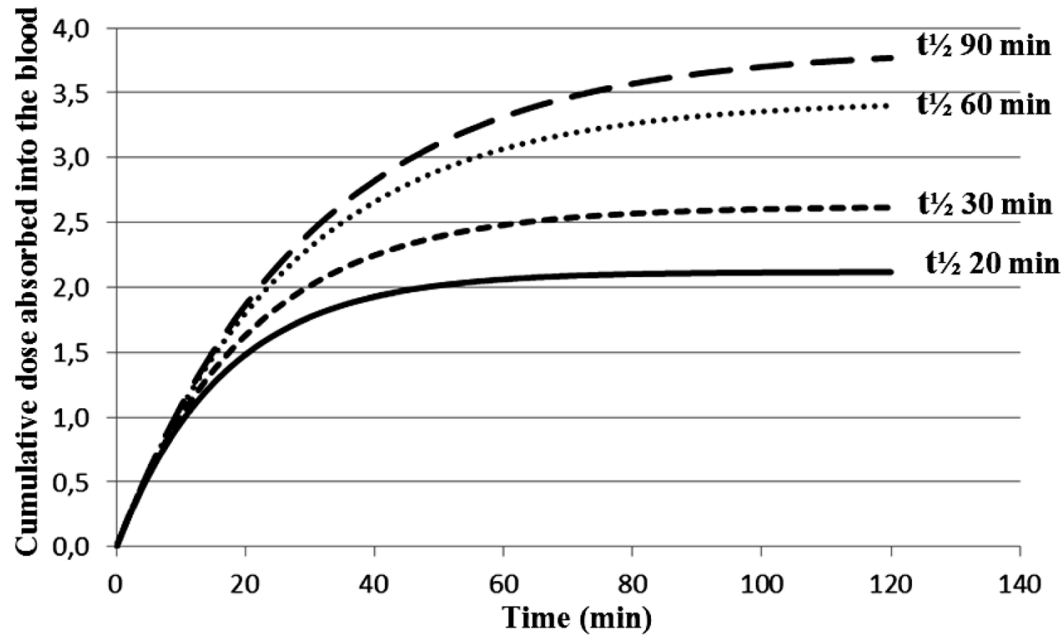

Fig. 7. A Cumulative Graph Showing the Impact of Delayed Clearance Following Intranasal Administration

The solid line represents a normal half-life inside the nasal cavity. The dotted lines are delayed mucociliary clearance.

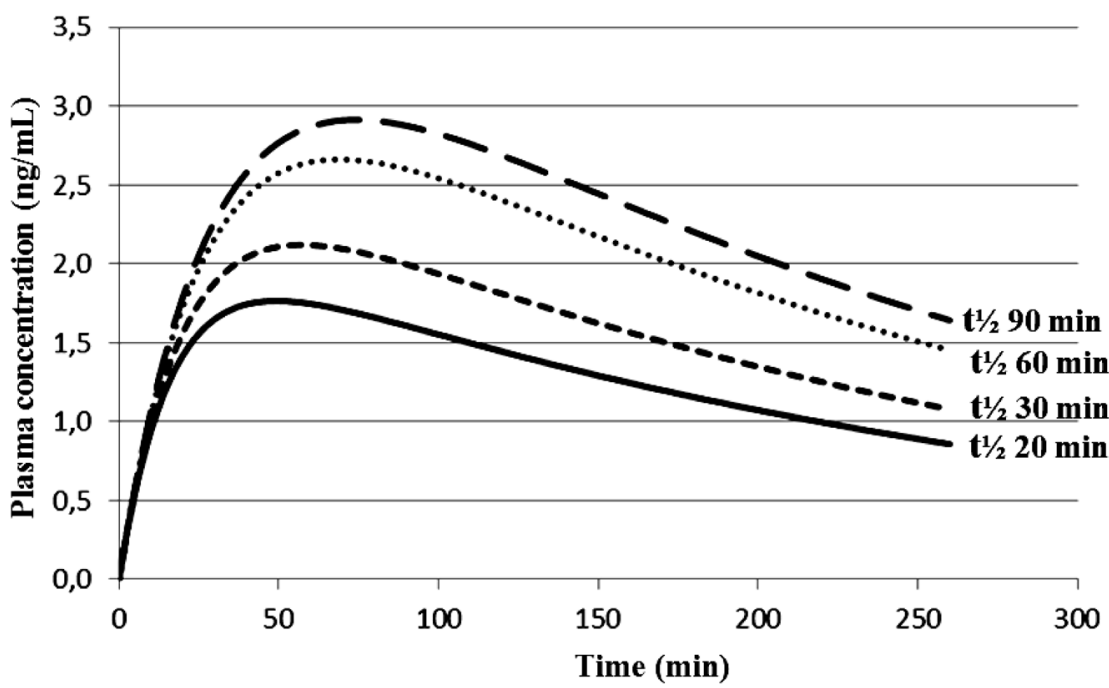

Fig. 8. A Simulation of Plasma-Concentration Profiles for Zolmitriptan Administered Intranasally Using One Compartment Model The solid line represents a normal half-life inside the nasal cavity. The dotted lines show delayed mucociliary clearance. 
Adding the plasma half-life $\left(k_{\mathrm{e}}\right)$ into the equations, a pure nasal absorption may be calculated according to following:

$$
[C]_{t}=\frac{[D]}{V_{\mathrm{d}}} \frac{k_{\mathrm{na}}}{\left(k_{\mathrm{na}}+k_{\mathrm{mc}}\right)-k_{\mathrm{e}}}\left(e^{-k_{\mathrm{c}} t}-e^{-\left(k_{\mathrm{na}}+k_{\mathrm{mc}}\right) t}\right)
$$

Using zolmitriptan as a model drug, Fig. 8 show a simulation of a plasma profile, based on a nasal absorption solely. The calculations are based on a fixed absorption rate constant although that may be modified using various excipients and formulations. In such case the graphs will show much different profiles.

\section{MUCOSAL IRRITATION AND DISEASES}

Nasal irritation may be divided into two categories, first is a direct damage to the nasal epithelia and second a sensory irritation to the nerve endings. In both cases nasal irritation is detected by the 5th cranial nerve (trigeminal nerve), resulting in a response from the 7 th cranial nerve (facial nerve) by increasing nasal secretion which will dilute the irritant, followed by increased mucociliary clearance. ${ }^{2)}$ Intranasal delivery of drugs or vaccines that cause irritation will be rapidly diluted, followed by increase clearance and swallowed. The result is a much shorter duration inside the nasal cavity and therefore less nasal bioavailability. Repeated administration of formulations containing slightly irritating drugs or excipients may additionally cause an increased size and number of goblet cells. ${ }^{89)}$ However, if the irritant is not diluted and removed, but allowed to stay attached to the nasal mucosa e.g. due to a mucoadhesive formulation, the irritant may gain time to induce significant damage to the mucosa.

Local and systemic diseases may also have an effect on the normal physiology of the nose and the absorption capacity of the nose. Patients having atrophic rhinitis or severe vasomotor rhinitis do not have good nasal condition for absorption.

Conflict of Interest The author declares no conflict of interest.

\section{REFERENCES}

1) Rogers DF. Physiology of airway mucus secretion and pathophysiology of hypersecretion. Respiratory Care, 52, 1134-1146, discussion, 1146-1149 (2007).

2) Gizurarson S. Anatomical and histological factors affecting intranasal drug and vaccine delivery. Curr. Drug Deliv., 9, 566-582 (2012).

3) Halama AR, Decreton S, Bijloos JM, Clement PAR. Density of epithelial cells in the normal human nose and the paranasal sinus mucosal. A scanning electron microscopic study. Rhinology, 28, 25-32 (1990).

4) Mygind N, Dahl R. Anatomy, physiology and function of the nasal cavities in health and disease. Adv. Drug Deliv. Rev., 29, 3-12 (1998).

5) Purkinjeand JE, Valentin G. De phaenomeno generali et fundamentalis motus vibratorii continui in membranis cum externis tum internis animalum plurimorum et superiorum et inferiorum ordinum obvii., Wratislaviae, Amsterdam (1835).

6) Fawcett DW, Porter KR. A study of the fine structure of ciliated epithelia. J. Morphol., 94, 221-281 (1954).

7) Laurenzi GA. The mucociliary stream. J. Occup. Med., 15, 175-176 (1973).
8) Chien YW, Su KSE, Chang SF. Anatomy and physiology of the nose, Marcel Dekker Inc., New York (1989).

9) Trindade SHK, de Mello JF Jr, Mion OdeG, Lorenzi-Filho E, Macchione M, Guimarães ET, Saldiva PH. Methods for studying mucociliary transport. Brazilian Journal of Otorhinolaryngology, 73, 704-712 (2007).

10) Afzelius BA. Cilia-related diseases. J. Pathol., 204, 470-477 (2004).

11) Satir P, Christensen ST. Overview of structure and function of mammalian cilia. Annu. Rev. Physiol., 69, 377-400 (2007).

12) Satir P, Christensen ST. Structure and function of mammalian cilia. Histochem. Cell Biol., 129, 687-693 (2008).

13) Baroody FM. Nasal and paranasal sinus anatomy and physiology. Clin. Allergy Immunol., 19, 1-21 (2007).

14) Lale AM, Mason JDT, Jones NS. Mucociliary transport and its assessment: a review. Clin. Otolaryngol., 23, 388-396 (1998).

15) Andersen I, Lundqvist GR, Proctor DF. Human nasal mucosal function in a controlled climate. Arch. Environ. Health, 23, 408-420 (1971).

16) Quinlan MF, Salman SD, Swift DL, Wagner HNJ Jr, Proctor DF. Measurement of mucociliary functions in man. Am. Rev. Respir. Dis., 99, 13-23 (1969).

17) Yates AL. Methods of estimating the activity of the ciliary epithelium within the sinuses. J. Laryngol. Otol., 39, 554-560 (1924).

18) Hilding A. Ciliary activity and course of secretion currents in the nose. Proceedings of Mayo Clinic, 6, 825-838 (1931).

19) App EM, Zayas JG, King M. Rheology of mucus and transepithelial potential difference: small airway versus trachea. Eur. Respir. J., 6, 67-75 (1993).

20) Rusznak C, Davalia JL, Lozewicz S, Davies RJ. The assessment of nasal mucociliary clearance and the effects of drugs. Respir. Med., 88, 89-101 (1994).

21) Stanley P, MacWilliam L, Greenstone M, Mackay I, Cole P. Efficacy of a saccharin test for screening to detect abnormal mucociliary clearance. Br. J. Dis. Chest, 78, 62-65 (1984).

22) Stanley PJ, Wilson R, Greenstone M, Mackay IS, Cole PJ. Abnormal nasal mucociliary clearance in patients with rhinitis and its relationship to concomitant chest disease. Br. J. Dis. Chest, 79, 77-82 (1985)

23) Yergin BM, Saketkhoo K, Michaelson ED, Serafini SM, Kovitz $\mathrm{K}$, Sackner MA. A roentgenographic method for measuring nasal mucus velocity. J. Appl. Physiol., 44, 964-968 (1978).

24) Corbo GM, Foresi A, Bonfitto P, Mugnano A, Agabiti N, Cole PJ. Measurement of nasal mucociliary clearance. Arch. Dis. Child., 64, 546-550 (1989).

25) Maurizi M, Paludetti G, Todisco T, Almadori G, Ottaviani F, Zappone C. Ciliary ultrastructure and nasal mucociliary clearance in chronic allergic rhinitis. Rhinology, 22, 233-240 (1984).

26) Mygind N. Topical steroid treatment for allergic rhinitis and allied conditions. Clin. Otolaryngol., 7, 343-352 (1982).

27) Watanabe K, Watanabe I. Morphological alterations affecting the microvascularture in nasal allergy. Ann. Otol. Rhinol. Laryngol., 92, 70-74 (1983).

28) Lund VJ. Nasal physiology. Neurochemical receptors, nasal cycle and ciliary action. Allergy Asthma Proc., 17, 179-184 (1996).

29) Habte HH, Mall AS, de Beer C, Lotz ZE, Kahn D. The role of crude human saliva and purified salivary MUC5B and MUC7 mucins in the inhibition of human immunodeficiency virus type 1 in an inhibition assay. Virol. J., 3, 99 (2006).

30) Sheehan JK, Kesimer M, Pickles R. Innate immunity and mucus structure and function. Novartis Fund Symposium, 279, 155-166 (2006).

31) Mall AS. Analysis of mucins: role in laboratory diagnosis. J. Clin. Pathol., 61, 1018-1024 (2008).

32) Boucher RC. Human airway ion transport. Am. J. Respir. Crit. Care Med., 150, 271-281 (1994).

33) Knowles MR, Boucher RC. Mucus clearance as a primary innate 
defense mechanism for mammalian airways. J. Clin. Invest., 109, 571-577 (2002).

34) Morgenroth K, Bolz J. Morphological features of the interaction between mucus and surfactant on the bronchial mucosa. Respiration, 47, 225-231 (1985)

35) Causey RC. Mucus and the mare: how little we know. Theriogenology, 68, 386-394 (2007).

36) Stannard W, O'Callaghan C. Ciliary function and the role of cilia in clearance. J. Aerosol Med., 19, 110-115 (2006).

37) Tarran R, Grubb BR, Parsons D, Picher M, Hirsh AJ, Davis CW, Boucher RC. The CF salt controversy: in vivo observations and therapeutic approaches. Mol. Cell, 8, 149-158 (2001).

38) Sleigh MA, Blake JR, Liron N. The propulsion of mucus by cilia. Am. Rev. Respir. Dis., 137, 726-741 (1988).

39) Smith DJ, Gaffney EA, Blake JR. Modeling mucociliary clearance. Respir. Physiol. Neurobiol., 163, 178-188 (2008).

40) Tarran R, Grubb BR, Gatzy J, Davis CW, Boucher RC. The relative roles of passive surface forces an dactive ion transport in the modulation of airway surface liquid volume and composition. J. Gen. Physiol., 118, 223-236 (2001).

41) Rogers DF. Airway goblet cell hyperplasia in asthma: hypersecretory and anti-inflammatory? Clin. Exp. Allergy, 32, 1124-1127 (2002).

42) Davies JR, Herrmann A, Russell W, Svitacheva N, Wickström C, Carlstedt I. Respiratory tract mucins: structure and expression patterns. Novoartis Found Symposium, 248, 76-88 (2002).

43) Finkbeiner WE. Physiology and pathology of tracheobronchial glands. Respir. Physiol., 118, 77-83 (1999).

44) Dell A, Morris HR. Glycoprotein structure determination by mass spectrometry. Science, 291, 2351-2356 (2001).

45) Perez-Vilar J, Mabolo R. Gel-forming mucins. Notions from in vitro studies. Histol. Histopathol., 22, 455-464 (2007).

46) Thornton DJ, Rousseau K, McGuckin MA. Structure and function of the polymeric mucins in airway mucus. Annu. Rev. Physiol., 70, 459-486 (2008).

47) Bernacki SH, Nelson AL, Abdullah L, Sheehan JK, Harris A, Davis $\mathrm{CW}$, Randell SH. Mucin gene expression during differentiation of human airway epithelia in vitro. Am. J. Respir. Cell Mol. Biol., 20, 595-604 (1999).

48) Martínez-Antón A, de Bolós C, Garrido M, Roca-Ferrer J, Barranco C, Alobid I, Xaubet A, Picado C, Mullol J. Mucin genes have different expression patterns in healthy and diseased upper airway mucosa. Clin. Exp. Allergy, 36, 448-457 (2006).

49) Audie JP, Janin A, Porchet N, Copin MC, Gosselin B, Aubert JP. Expression of human mucin genes in respiratory, digestive, and reproductive tracts ascertained by in situ hybridization. J. Histochem. Cytochem., 41, 1479-1485 (1993).

50) Kirkham S, Sheehan JK, Knight D, Richardson PS, Thornton DJ. Heterogenecity of airways mucus: variations in the amounts of glycoforms of the major oligomeric mucins MUC5AC and MUC5B. Biochem. J., 361, 537-546 (2002).

51) Gururaja TL, Ramasubbu N, Venugopalan P, Reddy MS, Ramalingam K, Levine MJ. Structure features of the human salivary mucin, MUC7. Glycoconj. J., 15, 457-467 (1998).

52) Rogers DF. The airway goblet cell. Int. J. Biochem. Cell Biol., 35, $1-6(2003)$.

53) Geurkink N. Nasal anatomy, physiology and function. J. Allergy Clin. Immunol., 72, 123-128 (1983).

54) Schipper NGM, Verhoef JC, Merkus FWHM. The nasal mucociliary clearance: relevance to nasal drug delivery. Pharm. Res., 8 , 807-814 (1991).

55) Illum L, Jörgensen H, Bisgaard H, Krogsgaard O, Rossing N. Bioadhesive microspheres as a potential nasal drug delivery system. Int. J. Pharm., 39, 189-199 (1987).

56) Burn JH, Day M. The action of tubocurarine and acetylcholine on ciliary movement. J. Physiol., 141, 520-526 (1958).

57) Burn JH. Acetylcholine as a local hormone for ciliary movement and the heart. Pharmacol. Rev., 6, 107-112 (1954).

58) Pavia D, Sutton PP, Lopez-Vidriero MT, Agnew JE, Clarke SW. Drug effects on mucociliary function. Eur. J. Respir. Dis., Suppl. 128, 304-317 (1983).

59) Jian L, Po ALW. Effect of xylometazoline and antazoline on ciliary beat frequency. Int. J. Pharm., 86, 59-67 (1992).

60) van de Donk HJ, Zuidema J, Merkus FW. The effects of nasal drops on the ciliary beat frequency of chicken embryo tracheas. Rhinology, 19, 215-230 (1981).

61) Donovan MD, Zhou M. Drug effects on in vivo clearance in rats. Int. J. Pharm., 116, 77-86 (1995).

62) Braga PC, Piatti G, Dal Sasso M, Bernini A. The effects of calcitonin nasal preparations and their excipients on mucociliary clearance in an ex-vivo frog palate test. J. Pharm. Pharmacol., 44, 938-940 (1992).

63) Iravani J, Melville GN. Long-term effect of cigarette smoke on mucociliary function in animals. Respiration, 31, 358-366 (1974).

64) Barton RPE, Gray RFE. The transport of crystalline cocaine in the nasal mucous blanket. J. Laryngol. Otol., 93, 1201-1204 (1979).

65) Song XH, Zhang L, Han DM, Wang H, Wang KJ. Effects of ephedrine on human nasal cilia movement measured with high-speed digital microscopy. Zhonghua Er Bi Yan Hou Tou Jing Wai Ke Za Zhi (Chin. J. Otorhinolaryngol. Head. Neck Surgery), 41, 583-586 (2006).

66) Gosselin RE. Physiologic regulators of ciliary motion, Duke University Medical Center Symposium on "Structure, Function and Measurement of Respiratory Cilia," Durham, North Carolina, pp. 18-19 (1965).

67) Braat JPM, Ainge G, Bowles JAK, Richards DH, van Riessen D, Visser WJ, Rijntjes E. The lack of effect of benzalkonium chloride on the cilia of the nasal mucosa in patients with perennial allergic rhinitis: a combined functional, light, scanning and transmission electron microscopy study. Clin. Exp. Allergy, 25, 957-965 (1995).

68) Jian L, Po ALW. Effects of insulin and nasal absorption enhancers on ciliary activity. Int. J. Pharm., 95, 101-104 (1993).

69) Gizurarson S, Marriott C, Martin GP, Bechgaard E. The influence of insulin and some excipients used in nasal insulin preparations on mucociliary clearance. Int. J. Pharm., 65, 243-247 (1990).

70) Ewert G. The effect of two topical anesthetic drugs on the mucus flow in the respiratory tract. Ann. Otol. Rhinol. Laryngol., 76, 359-367 (1967).

71) Su XY, Po ALW, Millership JS. Ciliotoxicity of intranasal formulations: menthol enantiomers. Chirality, 5, 58-60 (1993).

72) Dimova S, Mugabowindekwe R, Willems T, Brewster ME, Noppe M, Ludwig A, Jorissen M, Augustijns P. Safety-assessment of 3-methoxyquercetin as an antirhinoviral compound for nasal application: effect on ciliary beat frequency. Int. J. Pharm., 263, 95-103 (2003).

73) Song XH, Zhang L, Han DM, Wang KJ, Wang H, Zhang W. Effects of oxymetazoline hydrochloride on ex vivo human nasal cilia movement measured with high-speed digital microscopy. Zhonghua Er Bi Yan Hou Tou Jing Wai Ke Za Zhi (Chin. J. Otorhinolaryngol. Head. Neck Surgery), 43, 268-271 (2008).

74) Donk HJM, Merkus FWHM. Decreases in ciliary beat frequency due to intranasal administration of propranolol. J. Pharm. Sci., 71, 595-596 (1982)

75) Simon H, Drettner B, Jung B. Messung des schleimhaut-transportes in menschlichen Nase mit 51Cr markierten harzkugelchen. Acta Oto-Laryngology (Stockholm), 83, 378-389 (1977).

76) Remigius UA, Jorissen M, Willems T, Kinget R, Verbeke N. Mechanistic appraisal of the effects of some protease inhibitors on ciliary beat frequency in sequential cell culture system of human nasal epithelium. Eur. J. Pharm. Biopharm., 55, 283-289 (2003).

77) Batts AH, Marriott C, Martin GP, Bond SW. The effect of some preservatives used in nasal preparations on mucociliary clearance. J. Pharm. Pharmacol., 41, 156-159 (1989).

78) Morgan KT, Patterson DL, Gross EA. Responses of the nasal muco- 
ciliary apparatus to airborne irritants, McGraw-Hill Int., Washington (1986).

79) Aspden T, Illum L, Skaugrud Ö. The effect of chronic nasal application of chitosan solutions on cilia beat frequency in guinea pigs. Int. J. Pharm., 153, 137-146 (1997).

80) Aspden T, Adler J, Davis SS, Skaugrud Ö, Illum L. Chitosan as a nasal delivery system: evaluation of the effect of chitosan on mucociliary clearance rate in the frog palate model. Int. J. Pharm., 122, 69-78 (1995).

81) van de Donk HJ, van den Heuvel AG, Zuidema J, Merkus FW. The effects of nasal drops and their additives on human nasal mucociliary clearance. Rhinology, 20, 127-137 (1982).

82) Batts AH, Marriott C. The preservatives of nasal preparations. International Biodeterioration, 24, 7-15 (1988).

83) Tamaoki J, Kobayashi K, Sakai N, Kanemura T, Horii S, Isono K, Takeuchi S, Chiyotani A, Yamawaki I, Takizawa T. Atrial natriuretic factor inhibits ciliary motility in cultured rabbit tracheal epithelium. Am. J. Physiol., 260, C201-C205 (1991).

84) Wanner A, Salathe M, O'Riordan TG. Mucocilliary clearance in the airways. Am. J. Respir. Crit. Care Med., 154, 1868-1902 (1996).

85) Yang B, Schlosser RJ, McCaffrey TV. Dual signal transduction mechanisms modulate ciliary beat frequency in upper airway epithelium. Am. J. Physiol., 270, L745-L751 (1996).

86) Proctor DF, Anderson I, Lundqvist G. Clearance of inhaled particles from the human nose. Arch. Intern. Med., 131, 132-139 (1973).

87) Gizurarson S. Animal models for intranasal drug delivery studies. Acta Pharm. Nord., 2, 105-122 (1990).

88) Aoki FY, Crowley JCW. Distribution and removal of human serum albumin-technetium-99m instilled intranasally. Br. J. Clin. Pharmacol., 3, 869-878 (1976).

89) Lai SK, Wang YY, Wirtz D, Hanes J. Mucus-penetrating nanoparticles for drug and gene delivery to mucosal tissues. Adv. Drug Deliv. Rev., 61, 86-100 (2009). 